TRABALHOS LIVRES EIXO 2:

"PSICANÁLISE: DIÁlOGO NAS FRONTEIRAS" 


\section{A Recusa e o inconsciente não reprimido ${ }^{154}$}

\section{Vanessa Chreim 155}

Enquanto mecanismo de defesa, a Recusa não é muito familiar entre nós psicanalistas, sendo com frequência associada apenas à perversão. Entretanto, autores contemporâneos resgataram sua origem na obra de Freud e lhe conferiram atualidade ao abordar fenômenos em que a Recusa se manifesta. Trata-se de um amplo espectro, que inclui adoecimentos psíquicos, mas também aspectos constitutivos e não patológicos. Eles nos permitem compreender o alcance da afirmação de Freud, em Compêndio de Psicanálise (1940 [1938]) de que este mecanismo de defesa está presente em todas as formas de subjetivação.

Neste trabalho, não poderei abordar todas as dimensões da Recusa, mas ele é um convite a embrenharem-se no campo do inconsciente não reprimido, a que Freud faz referência em O Eu e o Id (1923): "Reconhecemos que o Ics não coincide com o reprimido; continua certo que todo reprimindo é ics, mas nem todo Ics é também reprimido" (p. 21). Este caminho nos permite explorar novas fronteiras e possibilita o desvelamento de outras dimensões do funcionamento do aparelho psíquico e suas perturbações. Ao abordar o âmbito das crenças e do trauma, constataremos que a Recusa é muito mais frequente na clínica do que supomos.

Embora a noção de Recusa esteja presente nos textos iniciais da obra de Freud, como em Sobre as teorias sexuais das crianças (1908) e em Análise de uma fobia em um menino de cinco anos (1909), foi nos textos que vieram quase vinte anos depois que a Recusa se tornou conceito. Na obra de Freud, o termo em alemão Verleugnung refere-se à Recusa, mas já foi traduzido de diversas formas, por exemplo: negação, denegação, rejeição, renegação e desmentido, por vez levando a mal-entendidos e imprecisões.

Em A organização Genital Infantil (1923), a Recusa é uma reação inicial não patológica ante a fantasia de castração. Segundo Freud, quando o menino vislumbra a vagina ele não concebe que a mulher tem um órgão sexual diferente,

\footnotetext{
154 Apresentado em Trabalhos livres no II Simpósio Bienal SBPSP "Fronteiras da Psicanálise: a clínica em movimento" no dia 28 de agosto de 2020.

155 Psicanalista, Mestre em Psicologia Clínica pela PUC-SP, membro do Departamento Formação em Psicanálise do Instituto Sedes Sapientiae.
} 
pelo contrário, ele presume que a ausência de pênis se refere a uma mutilação. Para o autor, essa visão é traumática e desperta uma tempestade de afetos, pois leva o menino a uma conclusão terrível: a de que a menina tinha um pênis que lhe foi tirado, como punição por seu desejo incestuoso. Consequentemente, o menino teme que ele também possa perder o seu genital, e por isso Recusa as consequências psíquicas da descoberta da diferença anatômica entre os sexos.

No entanto, toda experiência de descoberta sobre o mundo deve nos levar a uma revisão de nossas teorias sobre a vida, mas a Recusa impede este exercício de reflexão, uma vez que ele leva à contestação de crenças. Se a criança questionasse a sua fantasia do primado do falo, ela poderia ressignificar a fantasia de castração, porém, devido à ação da Recusa, a criança continua acreditando que todos tinham um pênis, mas os malcomportados o perderam. Neste sentido, em Algumas consequências psíquicas da diferença anatômica entre os sexos (1925), Freud nos alerta ao fato de que, se essa atitude se mantém na vida adulta, a Recusa pode levar a adoecimentos psíquicos.

Para podermos abordar esta questão de uma forma mais ampla e atual, precisamos superar a concretude da falta de pênis, e tomar a emblemática cena da descoberta das diferenças anatômicas entre os sexos como uma metáfora. Laplanche e Pontalis (2001) enfatizam que à mulher não falta um genital: a castração é uma fantasia. Neste sentido, a Recusa não se refere à não admissão da realidade material, e sim da realidade psíquica.

Mas o que significa admitir a castração? Segundo Clavreul (1990), o que está em jogo na cena descrita por Freud (1925) não é o objeto da descoberta, mas a mudança de posição subjetiva que ela provoca. Assim, para além da visão de um genital, a admissão da castração se refere à possibilidade de se impactar e se transformar afetivamente por experiências que nos colocam diante da alteridade e da perda, desde o início da vida, no movimento de presença e ausência da mãe (seio).

A partir do texto de Freud $A$ dissolução do complexo de Édipo (1924) podemos compreender que o complexo de Édipo envolve uma travessia em que o falo é metaforizado como um lugar no desejo do outro, e deixa de estar encarnado no órgão genital. Portanto, é esta elaboração que torna a castração admissível. Freud afirma que "Todo o processo, por um lado, salvou o genital, afastou dele o 
perigo da perda, e, por outro lado, paralisou-o, suspendeu sua função” (Freud, 2010 [1924], p. 209).

Por sua vez, Aulagnier-Spairani (2003) esclarece que é a articulação do desejo do casal parental que possibilita que a ausência seja encarada como presença - ausência de pênis e presença da vagina. A fantasia de castração pode então ser reinterpretada: ela deixa de equivaler a uma mutilação, e passa a representar uma diferença que causa desejo. Nesta triangulação, a criança se depara com o fato de que ela não é o único objeto de desejo de sua mãe: papai veio antes.

Deste modo, a admissão da castração engendra um processo psíquico que envolve uma série de feridas narcísicas, que para serem aceitas, precisam articular separação e ligação. Explico: de um lado a proibição do incesto determina a exclusividade da relação do casal parental, e impele à exogamia, mas de outro, é necessário que o filho possa manter alguma ligação com o circuito afetivo dos pais e com a herança familiar. Portanto, narcisismo, desejo e simbolização são aspectos intrínsecos à possibilidade de admitir a castração.

Porém, quando este processo de reinterpretação falha, a castração é impensável. Neste contexto, encontramos a origem do conceito de Recusa: uma proteção contra o horror da fantasia de castração, que causa a formação de duas correntes psíquicas opostas e simultâneas, em que a criança a aceita e, ao mesmo tempo, não a admite. Mas como se pode admitir e não admitir a castração? Significa que uma corrente psíquica derivou da visão da vagina, se ligou à fantasia do primado do falo, gerou a fantasia de castração, mas sob o impacto traumático recuou horrorizada. Assim sendo, Mannoni (1969) propõe que esta dupla atitude se expressa como "eu sei, mas mesmo assim" - que articula a admissão e subsequente não admissão da castração - sendo que a adversativa "mas mesmo assim” revela a ação da Recusa e a manutenção da crença.

O propósito defensivo é criar a ilusão de que o sujeito não foi impactado afetivamente pela experiência, como se nada tivesse acontecido. Deste modo, a Recusa intercede, no intuito de congelar o tempo, restituindo a posição subjetiva pré-traumática. O texto $O$ fetichismo (1927) esclarece este funcionamento psíquico: segundo Freud, o fetiche se constrói a partir da fixação na representação logo anterior à visão da vagina, e assim como a visão da medusa, paralisa o processo perceptivo. É através do superinvestimento no registro 
psíquico do momento pré-traumático que a Recusa impede a continuação do encadeamento das representações, que levariam a conclusões psíquicas inadmissíveis e despertariam afetos intoleráveis. Mas a própria emergência do processo defensivo testemunha que o psiquismo foi, de alguma forma, afetado pela percepção. Neste sentido, o fetiche condensa o horror e a proteção contra a castração.

Entretanto, é importante ressaltar que em Compêndio de psicanálise (1940 [1938]), Freud afirma que não é o fetiche que produz a Cisão do Eu, mas sim a atitude dividida derivada da Recusa, em que o Eu é o campo de batalha das forças psíquicas que se opõem quanto à relação com a realidade. Por sua vez, a função do fetiche é tentar remendar a cisão do Eu, como uma formação de compromisso, por meio da equação simbólica. Através do deslocamento, o valor do pênis (falo) da mãe é transferido para o fetiche, de modo que é possível articular uma lógica que afirma "a mulher não tem pênis, mas tampouco foi castrada" - uma vez que o falo está encarnado no fetiche.

O fetichismo nos revela que, não apenas a diferença sexual não é admitida, mas anterior a isto, não é admitida a hipótese de que falta algo à mãe. Neste contexto, sobrevive a crença na mãe fálica, que se opõe à admissão da castração, na medida em que sustenta a ilusão de uma mãe onipotente, a quem nada falta, que pode consertar tudo. Recusando a triangulação edípica, a crença na mãe fálica sustenta a ilusão de amor incondicional e exclusivo da mãe pelo filho.

Entretanto, não é sempre que as crenças produzem adoecimento psíquico. Elas são uma dimensão da Recusa que está presente em todos nós, porquanto nos oferece certezas reconfortantes em situações em que nos vemos muito ameaçados. Diante do duro pacote da castração, as crenças encarnam garantias ilusórias de proteção contra o medo da morte e da finitude, e contra o desamparo afetivo. Ritos e tradições preservam crenças culturais compartilhadas que dão um senso de pertencimento, segurança e continuidade. Cada um se apropria de sua herança social e familiar de uma forma particular. Desde que possam ser reformuladas e permeáveis a transformação, as crenças são meras interpretações da experiência humana.

No entanto, a perpetuação da ação da Recusa pode comprometer o funcionamento do aparelho psíquico. Penot (1992) considera que o sentimento de irrealidade é o primeiro sinal clínico da Recusa, como expressão da vivência 
do infamiliar, experiência que foi abordada por Freud no texto assim intitulado (no original, Das Unheimliche, 1919). Segundo Freud, este fenômeno refere-se a uma perturbação do senso de realidade, devido à ressureição de crenças que pensávamos já ter abandonado. Penot compreende que discursos familiares impenetráveis, inquestionáveis e não reinterpretáveis geram crenças aprisionadoras. Estas sobrevivem apesar das vivências que as contestam, podendo assombrar-nos como mortos vivos. Assim como um dogma de uma voz interna ou um imperativo que ordena não mencionar a castração materna, as crenças podem desapropriar o sujeito de sua própria experiência emocional.

Mas quando fica agarrado a certezas absolutas, o psiquismo fica impedido de aprender com a experiência e impedido de elaborá-la emocionalmente. A blindagem que a Recusa confere à crença faz com que ela se torne patológica e intransigente, na medida em que aprisiona o movimento psíquico e promove um fechamento. Neste processo, que Figueiredo (2008) chama de desautorização, as relações entre representações não se abrem a novos elementos e à possibilidade de compor novos sentidos, no intuito de que o registro da experiência traumática seja invalidado. Deste modo, a Recusa impede o trânsito dos processos psíquicos, amortecendo o choque traumático, porém, perturbando a possibilidade de simbolização. O psiquismo pode tornar-se enrijecido e empobrecido, resistente a transformações, e cada vez mais obsoleto e vulnerável, quando deixa de desenvolver a capacidade para tolerar tensões psíquicas e turbulências. Perdas, separações, decepções amorosas e morte fazem parte da vida de todos, e é preciso desenvolver recursos psíquicos para tolerar e conviver com estas facetas inevitáveis da castração.

\section{Referências}

Aulagnier-Spairani, P. A perversão como estrutura. Revista latino-americana de psicopatologia fundamental. São Paulo: 2003, v. 6, n. 3.

Clavreul, J. O casal perverso. In: CLAVREUL, J. et al. $O$ desejo e a perversão. Campinas: Papirus, 1990.

Figueiredo, L. C. Psicanálise: elementos para a clínica contemporânea. São Paulo: Escuta, 2008.

Freud, S. (1940 [1938]). A cisão do Eu no processo de defesa. In: Freud, S. Obras Completas. São Paulo: Companhia das Letras, 2010.

Freud, S. (1924). A dissolução do complexo de Édipo. In: Freud, S. Obras Completas. São Paulo: Companhia das Letras, 2010. 
Freud, S. (1923). A organização genital infantil. In: Freud, S. Obras Completas. São Paulo: Companhia das Letras, 2010.

Freud, S. (1925). Algumas consequências psíquicas da diferença anatômica entre os sexos. In: Freud, S. Obras Completas. São Paulo: Companhia das Letras, 2010. Freud, S. (1909). Análise de uma fobia em um menino de cinco anos. In: Freud, S. Edição Standard Brasileira das Obras Psicológicas Completas de Sigmund Freud. Rio de Janeiro: Imago, 2006.

Freud, S. (1940 [1938]). Compêndio de psicanálise. In: Freud, S. Obras Completas. São Paulo: Companhia das Letras, 2010.

Freud, S. (1923). O Eu e o Id. In: Freud, S. Obras Completas. São Paulo: Companhia das Letras, 2010

Freud, S. (1919). O infamiliar [Das Unheimliche]: seguido de O homem da areia de E. T. A. Hoffmann . In: Freud, S. Obras incompletas de Sigmund Freud. São Paulo: Autêntica, 2019.

Freud, S. (1927). O Fetichismo. In: Freud, S. Obras Completas. São Paulo: Companhia das Letras, 2010.

Freud, S. (1908). Sobre as teorias sexuais das crianças. In: Freud, S. Edição Standard Brasileira das Obras Psicológicas Completas de Sigmund Freud. Rio de Janeiro: Imago, 2006.

Laplanche, J.; Pontalis, J. B. Vocabulário da psicanálise. São Paulo: Martins Fontes, 2001.

Mannoni, O. Eu sei, mas mesmo assim (1969). In: KATZ, C.M. (org). Psicose. São Paulo: Escuta, 1991.

Penot, B. Figuras da recusa: Aquém do Negativo. Porto Alegre: Artes Médicas, 1992. 